\title{
A cien años del grito de Córdoba y a cincuenta años de mayo de 1968
}

\author{
Marcel Thezá Manríquez \\ Universidad de Los Lagos, Osorno, Chile. \\ Email: marcel.theza@ulagos.cl
}

La Universidad de Los Lagos fue creada el 30 de agosto de 1993 como Universidad del Estadocon una profunda identidad y vocación regional. Nuestra institución se transformaba, de esta forma, en la heredera directa de lo que en los años sesenta fuese la instalación del Centro Regional de la Universidad de Chile en Osorno, Centro transformado posteriormente en Sede en 1972.

En el marco de las profundas transformaciones institucionales que afectaron al sistema de educación superior en 1981, esta Sede, junto con la Sede Puerto Montt de la Universidad Técnica del Estado, pasaron a constituir el Instituto Profesional de Osorno; antecedente inmediato al nacimiento de lo que hoy es nuestra Universidad.

Precisamente esta ceremonia se constituye en una de las primeras actividades oficiales conducentes a la conmemoración de los 25 años de vida de una institución profundamente comprometida e imbricada con todos los procesos experimentados por las universidades del Estado en estas casi cuatro décadas.En todos estos años, la Universidad de Los Lagosha respondido al compromiso - suscrito con el País y la Región- de cumplir un conjunto de objetivos que nos han provisto de propósito y que le han dado sentido a nuestro quehacer y a nuestro trabajo; entre ellos encontramos:

Primero) El participar activamente en la identificación, estudio y formulación de propuestas de solución a los problemas del medio en que nuestra Universidad se inserta.

Segundo) El cumplir un rol integrador entre la realidad regional y el sentido de unidad que requiere la nación; esto mediante el estudio, cultivo y promoción de las actividades culturales y artísticas.

Y, por último) El asumir responsablemente el principio de equidad como propósito permanente, mediante mecanismos que entreguen posibilidades de estudio para aquellos jóvenes que, teniendo la capacidad intelectual suficiente, no cuentan con recursos económicos para financiar sus estudios.

Como antecedentes, señalo que para la generación 2018, no es baladí recordar, por ejemplo, que la gratuidad en nuestra institución bordea el 
$75 \%$, que existe una matrícula femenina del $58 \%$, que el 38\% de los estudiantes de los Campus Osorno y Pto. Montt, se reconocen de ascendencia mapuche, y que el 98\% de los estudiantes de los mismos campus provienen de colegios municipales (50\%) y subvencionados (48\%).

La Universidad de Los Lagos se ha definido como una entidad académica de educación superior de tipo estatal, autónoma y regional, con un sentido democrático y humanista.

- Estatal, por nuestra arquitectura institucional y por el espacio al cual pertenecemos y del cual orgullosamente nutrimosnuestros objetivos; pero estatal también en nuestra misión,lo que nos obliga a observar con objetividad y apertura los llamados "problemas de sociedad” - precisamente de un tipo de sociedad más compleja - pero también a participar activa y colaborativamente en la búsqueda de las soluciones para un "mejor vivir”.

- Autónoma, lo que implica una rigurosa autorregulación administrativa y económica, estableciendo nuestra propia forma de organización interna. Así también,autorregulación académica, materializando la libertad de cátedra y de investigación, y definiendo libremente nuestras áreas de desarrollo y nuestras prioridades mediante criterios estrictamente académicos.

- Pero también,Regional, rasgo que nos confiere una dimensión distintiva y que nos obligaa atender prioritariamente la vinculación con la macro región austral donde el corazón de la Universidad late y desde donde se nos vertebra; rasgo - el regional - que también nos instala en un ámbito de preocupaciones generales donde la Universidad piensa consistentemente el desarrollo, la cohesión y la gobernanza territorial como temáticas y desafíos no estrictamente circunscritos, menos aún limitados, al territorio administrativo en que la Institución se inserta.

Precisamente, las características que he nombrado, también nos obligan al cumplimiento de otro tipo de responsabilidades que son las responsabilidades de memoria, las responsabilidades de saber tejer el hilo - a veces confuso, a veces delicado- entre pasado, presente y porvenir. El resguardo de ese hilo esencial que la antigüedad reservaba a la Moira (buena para algunos, mala para otros), nuestro tiempo la reserva a Instituciones que hoy casi contraculturalmente debemos recordar que, ni nosotros ni nuestras instituciones, somos el resultado de un "eterno presente”, sino más bien de dinámicas profundas que han ido moldeando en el tiempo - y lo seguirán haciendo - lo que hoy somos como Continente, lo que somos como País y lo que somos como Región. Por ello, las instituciones del Estado tenemos una misión irrenunciable con la preservación de la memoria y sobre todo con el uso relevante de ella para nuestro presente y porvenir. Lo anterior a partirde lo que otros hombres y mujeres han producido como hechos determinantes y significantes, sin los cuales lo que hoy somos simplemente no tendría sentido. 
Por lo tanto, la reconstrucción de memoria no es puro ejercicio académico; es comprender con claves atávicas nuestros nuevos escollos y desafíos.

Es por este sencillo - pero no menos complejo - motivo que para la inauguración de nuestro año académico nos pareció relevante hacer un ejercicio de memoria, conmemorando, reflexiva y articuladamente, dos hitos que a muchas generaciones nos han marcado política y simbólicamente; me refiero a los cien años de la Reforma de Córdoba (llamada grito de Córdoba) y a los cincuenta años del movimiento universitario francés de mayo de 1968.

La elección de tales hitos es, por cierto, arbitraria y no busca desdibujar, menos aún olvidar, nuestros propios procesos de reforma en Chile.

Sin pretender complejizar las fronteras acordadas de esta actividad, debo admitir que el propio concepto de Reforma anuncia las dificultades de nuestro tema. La dialéctica entre cambio, conservación e institucionalización, muchas veces nos ha puesto en veredas distintas al intentar apropiarnos de este término como explicativo delo que cada uno de nosotros entiende como una transformación notable en relación a un estado anterior.

Quizá, por ello, una primera pregunta sugerente sería: ¿estos movimientos desencadenaron efectivamente reformas?

Una segunda pregunta podría ser, ¿̇no fueron éstos acaso más bien procesos de ruptura de tipo más general donde la Universidad catalizó y expresó expectativas de integración de sociedades que habían cambiado y que no encontraban respuestas a ese deseo vehemente de cambio en sus propias instituciones?

La tercera pregunta no la formulo directamente, más que por economía, por lógica,puesto que creo que cada uno de nosotros y nosotras la estamos dibujando individualmente, pero intuyo que claramente nos lleva a pensarlas experiencias históricas que serán detalladas en comparación a las que hoy vive Chile, pensando que éstasno dejan de asemejarse bastante en varios aspectos.

La Reforma de Córdoba de 1918 ha sido señalada como el primer cuestionamiento serio de la universidad latinoamericana tradicional. La renovada función social de la universidad, la autonomía universitaria, así como la elección de sus autoridades por claustros tripartitos, han sido en distintos momentos banderas de lucha de la mayoría de las universidades de América Latina.

El Manifiesto Liminar, nombre dado a la proclama del movimiento de reforma de la Universidad Nacional de Córdoba del 21 de junio de 1918 señalaba con tono provocador, pero también seductor 
“Hombres de una República libre, acabamos de romper la última cadena que, en pleno siglo $\mathrm{XX}$, nos ataba a la antigua dominación monárquica y monástica. Hemos resuelto llamar a todas las cosas por el nombre que tienen. Córdoba se redime. Desde hoy contamos para el país una vergüenza menos y una libertad más. Los dolores que quedan son las libertades que faltan. Creemos no equivocarnos, las resonancias del corazón nos lo advierten: estamos pisando sobre una revolución, estamos viviendo una hora americana”

Ahora bien, el movimiento universitario de Coìrdoba, en tanto sujeto político colectivo, ha sido recurrentemente explicadoa partir de las condiciones expansivas del régimendemocrático en que éste surge y por ello el tenor de su orientación ha polarizado su interpretación. Para el mundo liberal este movimiento es, como otros, el resultado lógico de un proceso general de expansión de las clases medias. Para otros, es el caso de Mariátegui, él constituye, él representa, un ejercicioreformista de tipo progresista dado el eje relevante que el tema de la función social de la universidad adquiere.

Por su parte, el movimiento de mayo 1968, que comienza en rigor el 22 de marzo en la nueva Facultad de Nanterre,surge de la acción de un grupo de estudiantes que ocupa la Sala de Consejo de la Universidad. Posteriormente el movimiento se propaga alcanzando a la Sorbonne y otras universidades de Paris, así como de otras provincias de Francia. Luego los obreros y sus organizaciones solidarizarán con los estudiantes a través de diversas acciones y con una huelga general de gran magnitud el día 13 de mayo de 1968 .

El escenario con la Argentina de 1918 parece tener algunas similitudes. Francia había crecido después de la post guerra, pero las expectativas de redistribución no satisfacían a toda la sociedad. Por ello en materia de interpretación sobre el alcance de los acontecimientos de mayo de 1968, dos planteamientos principales se afrontan; por una lado, el que argumenta que él es representativo de la generalización de la sociedad de consumo y del individualismo, versus el que percibe, muy por el contrario, una clara aspiración a una nueva forma de autonomía universitaria y esencialmente a un nuevo proyecto de sociedad.

El sólido pensador conservador, Raymon Aron, señalaba con juicio diacrónico que Mayo de 68 representaba lo más evidente de la vulnerabilidad de la sociedad francesa, a saber la debilidad de sus cuerpos intermedios (más específicamente de su no sindicalización de obreros) lo que dejaba el campo libre a las minorías en cada periodo de crisis; esto desde la Revolución francesa en adelante.

Por su parte, autores como Luc Ferry y Alain Renaut abren aún mucho más el campo interpretativo de Mayo de 1968, señalando que éste ha sido entendido desde perspectivas muy divergentes; a saber, como: 1) un complot de izquierdistas, 2) como una crisis exclusiva de universidad, 3) como una revuelta generacional, 4) como una crisis de civilización, 5) como 
un nuevo tipo de conflicto de clases, 6) como un conflicto social tradicional, 7) como una crisis política, o simplemente, como se afirma habitualmente, 8) como un encadenamiento de circunstancias.

Insisto que en ambos casos resaltan ciertos fenómenos que nos hacen pensar en el Chile de hoy y creo que eso será parte de las reflexiones de esta tarde. Entre ellos: a) La universidad como catalizadora de procesos generales de cambio de la sociedad y de ruptura con el sistema institucional del momento, b) La Universidad como expresión de expectativas de inclusión e integración a través del tema de los derechos en general, c) La Universidad como expresión de expectativas de inclusión e integración a través de la educación como aspecto particular (varios estudios en Chile definen hoy en día a la educación -sobre todo la superior -como "la puerta mágica”; esto en materia de imaginarios de integración). Pero también es interesante destacar d) La notable mezcla que el discurso estudiantil ha esgrimido en todos los casos históricos que nos preocupan, combinando aspectos de tipo corporativo, de tipo político y sobre todo de tipo moral.

\section{Agradecimientos}

Intervención en la inauguración del año académico de la Universidad de los Lagos, Sede Santiago, 24 de abril 2018. 